\title{
$\mathrm{M} \& \mathrm{~S}$ 기법을 통한 레이다 상호 간 전파 간섭 분석
}

\section{Analysis of Radar Interference Using a Modeling and Simulation Method}

\author{
박명훈 · 권세웅 · 전우중 · 김현승 · 유승기 · 이기원 \\ Myung-Hoon Park $\cdot$ Se-Woong Kwon $\cdot$ Woo-Joong Jeon $\cdot$ Hyun-Seung Kim $\cdot$ Seung-Ki You $\cdot$ Ki-Won Lee
}

요 약

산악지형이 많은 곳에서 레이다를 운용할 때에는 차폐 구역을 줄이기 위해 상대적으로 많은 레이다가 필요하고, 복잡 한 빔 운용이 요구된다. 이로 인해 주파수 자원이 부족한 환경에서 레이다 간 거리가 점차 가까워지면서 상호 전파 간섭 발생 빈도가 많아지고 있다. 간섭 신호는 레이다의 탐지 성능을 저하시키기 때문에 지속적으로 신호를 검출하고, 회피해 야 하지만 빔이 많아지고 운용이 복잡해져 이를 예측하고 대응하기란 쉽지 않다. 이를 위해 본 논문에서는 레이다 간 전파 간섭을 예측하고 분석하기 위해 실제 주파수와 빔 운용을 반영한 $\mathrm{M} \& \mathrm{~S}$ 도구를 개발하고, 주파수 운용 시나리오에 따른 전파 간섭 영향성을 평가하였다.

\section{Abstract}

To provide adequate radar coverage in an area with mountainous terrain, we require multiple radar stations and complex beam operations to reduce the blocking area. Consequently, the distance between two radar stations is reduced, which causes radio interference due to insufficient frequency bands and reduces the detection performance of the radar system. To prevent this, interference must be detected and avoided. However, it is difficult to predict and respond to interference as the beam operation is complicated. In this study, we developed a modeling and simulation(M\&S) method that uses the actual frequency and beam operation to analyze interference and evaluated its effectiveness at different operating frequencies.

Key words: Radar Interference, Interference Prediction, FDR, Modeling and Simulation

\section{I. 서 론}

국내에서 사용 가능한 주파수 자원은 매우 한정적이어 서 통신, 군사, 방송 등의 다양한 분야에 각각의 고유 주 파수를 할당하기란 불가능하다. 그렇다 보니 각 분야에서 전파 간섭은 증가하고 있으며, 피할 수 없는 문제이다.

특히 군사 분야에서는 감시정찰 체계의 중요성이 증가 함에 따라 레이다 수가 많아지고 있어 시공간적으로 레
이다 간 전파간섭이 증가하고 있다 ${ }^{[1],[2]}$. 전파 간섭은 탐지성 능을 저하시키는 위험 요소로서 레이다 운용 시 필히 고려 해야 한다. 현재 전파 간섭을 대처하기 위한 도구는 부족 한 상황 속에서 계속되는 동일 대역 안에서의 무기 체계 증가로 전파 간섭을 예측하고 대응하는 것은 불가피하다. 레이다는 수신기 대역폭을 기준으로 일정 부분 주파수 를 이격하여 레이다의 운용 주파수를 사용한다. 이때 대 역 내에서 겹치는 주파수가 있으면 유동성을 높이기 위

(주)LIG 넥스원(LIG Nex1 Co., Ltd.)

- Manuscript received July 18, 2019 ; Revised September 27, 2019 ; Accepted October 17, 2019. (ID No. 20190718-067)

- Corresponding Author: Myung-Hoon Park (e-mail: myunghoon.park@lignex1.com) 
해 주파수 간격을 수신신호 대역폭보다 좁게 설정한다. 하지만 설정한 두 주파수 간격이 좁으면 수신채널 간 간 섭이 발생한다. 레이다 간 전파 간섭은 다양한 주파수 및 빔 운용에 따라 임의적으로 나타나고, 특히 펄스도플러 레이다에서는 통신용 모델과는 다르게 시간 개념이 포함 되어 나타난다. 임의적으로 나타나는 전파 간섭을 예측하 고 줄이기 위해 다양한 측면에서 레이다 간 간섭 영향을 분석하는 연구가 진행되어 왔다. 하지만 기존 진행된 연 구에는 실제 사용되는 레이다의 빔 운용, 주파수 운용이 고려되지 않아 레이다 상호간 전파 간섭의 영향성을 정 확하게 파악하기에는 한계가 있다 ${ }^{[3] \sim[5]}$.

본 논문에서는 이러한 한계점을 극복하기 위해 실제 레이다에서 사용되는 빔 운용을 모사한 M\&S(Modeling and Simulation) 도구를 개발하고, 주파수 운용에 따른 레 이다 간 상호 전파 간섭 영향성을 분석하였다. 이를 위해 2장에서는 구성된 M\&S 도구의 상세 모델을 설명하였고, 3 장에서는 간섭원으로부터 피간섭원에 수신되는 간섭 크 기, 주파수 가용성, 간섭 받은 레이다 회전 비율 결과를 2 가지 주파수 운용 시나리오를 통해 비교 분석하였다.

\section{II. 간섭 영향 분석 M\&S 모델}

레이다 성능예측 $\mathrm{M} \& \mathrm{~S}$ 는 레이다 체계성능에 영향을 주 는 다양한 요소들을 표현하고, 수학적, 논리적으로 모델 링하여 연속시간을 기반으로 실체계의 운용환경과 성능 을 예측하는 것이다. 본 논문에서는 주파수 운용에 따른 전파 간섭 영향성을 분석하기 위해 그림 1 과 같이 모델을 구성하였다. 크게 간섭원, 피간섭원, 운용환경으로 구분 되며, 레이다의 부체계의 기능을 위해 빔 운용, 주파수 운 용, 레이다 방정식, FDR(Frequency Dependent Rejection)로 구성하였다. 또한 주변 환경을 모의하기 위해서 대기 전 파 환경 모델과 기상 및 지형 데이터를 이용하여 구성하 였다. 각 부체계의 세부내용은 그림 1 과 같다.

\section{2-1 빔 운용 모델}

빔 운용 모델은 구동 모델과 빔 패턴 모델로 구성된다. 구동 모델의 경우, 레이다의 빔 방사와 회전 기능을 모의 하며, 빔 패턴 모델의 경우 실제 측정된 안테나 패턴을 기

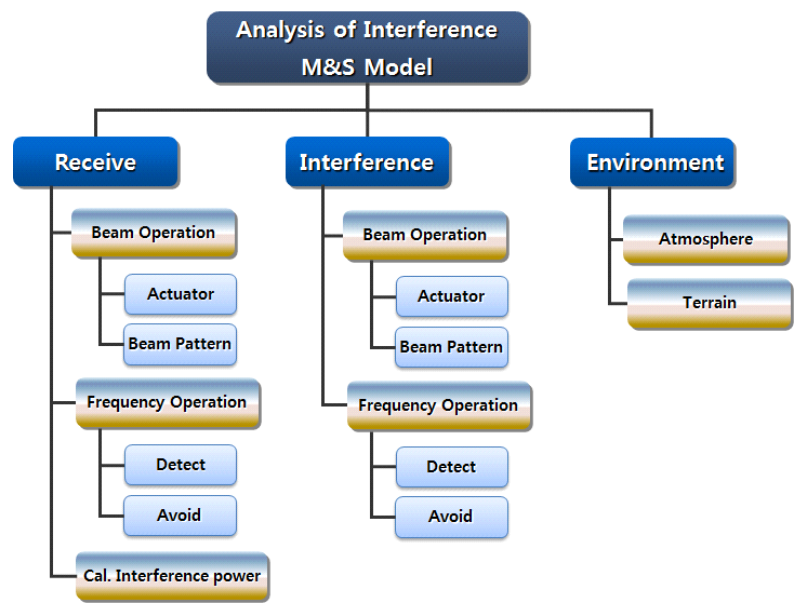

그림 1. M\&S 모델 구성도

Fig. 1. The structure of M\&S model.

반으로 빔 손실 및 부엽의 영향성을 모의한다.

\section{2-1-1 구동 모델}

구동 모델은 레이다의 빔 방사 특성을 이용하여 레이다 의 회전을 모사한다. 모의하는 레이다는 여러 빔으로 구성 되어 있으며, 각각 서로 다른 burst로 구성되어 있다. Burst는 하나의 빔이 표적에 대해 처리되는 기본 단위이며, 펄스 수 및 PRI(Pulse Repetition Interval)로 구성된 burst는 식 (1)과 같이 $\mathrm{RPM}$ (Revolution Per Minute) 정보를 이용하여 각도로 환산 되고, 그 값을 이용하여 레이다의 구동을 표현할 수 있다. 레이다는 서로 다른 환경에서 운용되기 때문에 각 환 경에 맞게 서로 다른 빔 패턴 및 파형, 방사 순서 및 고각 을 가진다. 서로 다른 빔 운용에 대한 영향성을 반영하기 위해 그림 2와 같이 가장 적은 $\mathrm{PRI}$ 를 가지는 펄스 시간을 시뮬레이션 간격으로 사용하였다.

$$
\triangle \operatorname{deg}=360^{\circ} \times P u l s e N \times P R I \times \frac{R P M}{60}
$$

\section{2-1-2 빔 패턴모델}

송수신 빔 패턴은 후방 산란(Back scattering)을 제외한 기준 방향(Boresight)을 기준으로 $-90^{\circ} \sim+90^{\circ}$ 에서 측정 된 안테나 빔 패턴을 사용하였다. 사용된 빔 패턴 결과는 그림 3 과 같다. 


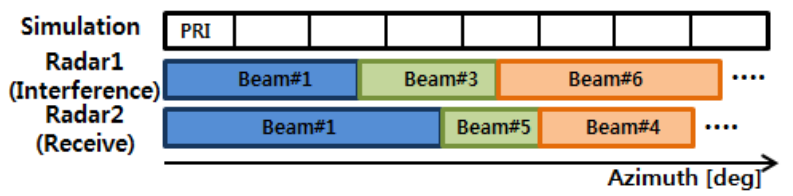

그림 2. 빔 방사 시간 개념

Fig. 2. The concept of beam scheduling.

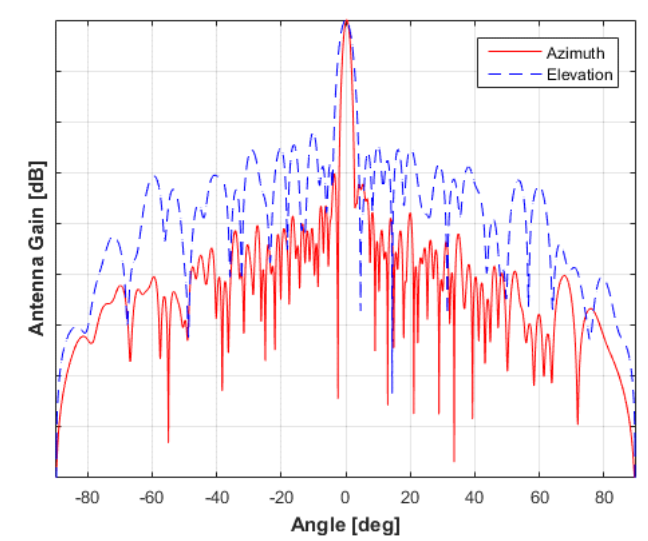

(a) 송신

(a) Transmission

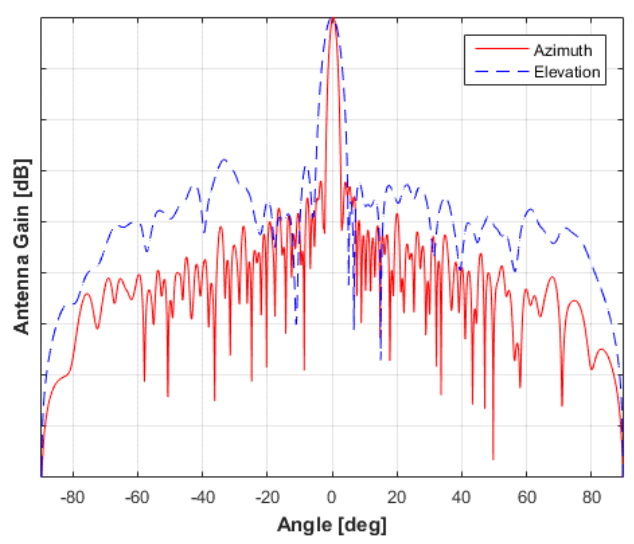

(b) 수신

(b) Reception

그림 3. 안테나 빔 패턴

Fig. 3. The antenna beam pattern.

\section{2-2 주파수 운용 모델}

\section{2-2-1 검출 모델}

검출 모델은 피간섭원에 전파 간섭이 발생하였는지를 판단하는 모델이다. 레이다는 각 빔을 방사하기 전에 빔

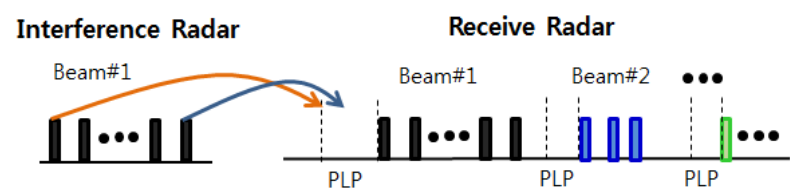

그림 4. 간섭 검출 개념

Fig. 4. The concept of interference detection.

상태 및 간섭 등을 검사하는 시간(passive listening period: PLP)을 가진다. 그림 4와 같이 피간섭원 레이다의 PLP 시 간 동안 간섭원 펄스 신호가 일정 크기 이상으로 들어오 면 간섭으로 간주한다.

서로 다른 송신 시간을 가지는 두 레이다는 다음 식 (2) 및 (3)과 같은 관계식을 통해 간섭 신호의 수신 여부를 판 단한다. 간섭 시간과 크기가 모두 만족할 경우, 회피 모델 에게 정보를 전달한다.

$$
\begin{aligned}
\mid\left(S T_{I}(i-1)+P R I \times\right. & (N-1)+R / 150) \\
& -\left(S T_{R}(i)\right) \mid \leq 100
\end{aligned}
$$

Jamming Power $\geq$ Sensitivity

$S T_{I}$ : 간섭원 레이다의 펄스 송신 시간 (us)

$S T_{R}$ : 피간섭원 레이다의 펄스 송신 시간 (us)

$R$ : 레이다 상호간 거리 $(\mathrm{m})$

$N$ : 펄스 번호

$i$ : 현재 계산 값

Sensitivity: 임계치 $(\mathrm{dB})$

\section{2-2-2 회피 모델}

회피 모델은 검출 모델로부터 정보가 넘어오면 간섭을 줄이기 위해 해당 주파수는 삭제하고, 동시에 임의적으로 다른 주파수로 이격하는 기능을 한다. 또한 삭제된 주파 수는 레이다 10 회전 이후 복원되어 다시 사용된다.

\section{2-3 간섭 크기 계산 모델}

운용 주파수에 따른 전파 간섭의 영향성은 $F D R$ 을 통 해 반영할 수 있다. $F D R$ 은 식 (4)와 같이 간섭원과 피간 섭원의 송수신 대역폭의 겹침 정도에 의해 결정되는 지 표이다[5],[6]. 이때 $P(f)$ 는 송신 신호 전력 스펙트럼 밀도 
이고, $H(f)$ 는 수신기 주파수 응답이다.

$$
F D R(\triangle f)=\frac{\int_{0}^{\infty} P(f) d f}{\int_{0}^{\infty} P(f)|H(f+\triangle f)|^{2} d f}
$$

최종적으로 간섭 레이다로부터 받은 피간섭 레이다에 수신된 전파 간섭 전력 크기는 식 (5)를 통해 구할 수 있 다 ${ }^{[5] \sim[7]}$. 이때 송수신 안테나 이득은 정해진 빔 스케쥴링 에 따른 빔 송수신의 방위각 및 고각이 고려되어 적용된 다. 주파수가 $100 \%$ 겹칠 경우 $F D R$ 값은 ' 1 '로 간섭 수신 전력 크기가 최대가 되고, 겹치지 않을 경우 $F D R$ 값은 무 한히 큰 간섭 전력 크기를 가진다.

$$
P_{r}=\left(\frac{P_{I} G_{I} G_{r} \lambda_{r}^{2}}{(4 \pi)^{2} R^{2} B_{I} L F D R}\right)
$$

$P_{r}$ : 간섭 전력 크기 $(\mathrm{W})$

$P_{I}$ : 간섭 레이다 송신 전력 크기 $(\mathrm{W})$

$G_{I}$ : 간섭 레이다 송신이득 $(\mathrm{W} / \mathrm{W})$

$B_{I}$ : 간섭 레이다 대역폭 $(\mathrm{Hz})$

$G_{r}$ : 피간섭 레이다 수신이득 $(\mathrm{W} / \mathrm{W})$

$\lambda_{r}$ : 피간섭 레이다 파장 $(\mathrm{m})$

$F D R$ : 주파수간 겹침 정도 $(\mathrm{W} / \mathrm{W})$

$R:$ 거리 $(\mathrm{m})$

$L$ : 손실 $(\mathrm{W} / \mathrm{W})$

\section{2-4 운용 환경 모델}

운용 환경 모델에는 전파전파를 모의하는 대기 전파 환경 모델과 레이다의 주변 환경을 반영한 대기/지형 데 이터로 구성된다. 레이다의 운용 시공간 요소를 반영하여 전파 환경을 계산하는 APM(Advanced Propagation Model) 을 통해 간섭 및 피간섭원 레이다 사이의 전파 손실을 모 의하였다. 계산된 손실값에는 레이다 빔 성능, 패턴, 대기 굴절률, 지형이 반영된다. 모의하는 레이다의 경우, 여러 펜슬 빔을 방사하는데 각 빔은 서로 다른 빔 패턴과 파형 성능을 가지고 운용된다. 서로 다른 빔 정보는 $\mathrm{APM}$ 을 통 해 서로 다른 손실값을 가지게 된다 ${ }^{[8]}$.

구성된 모델은 그림 5 와 같은 순서로 수행된다. 레이다

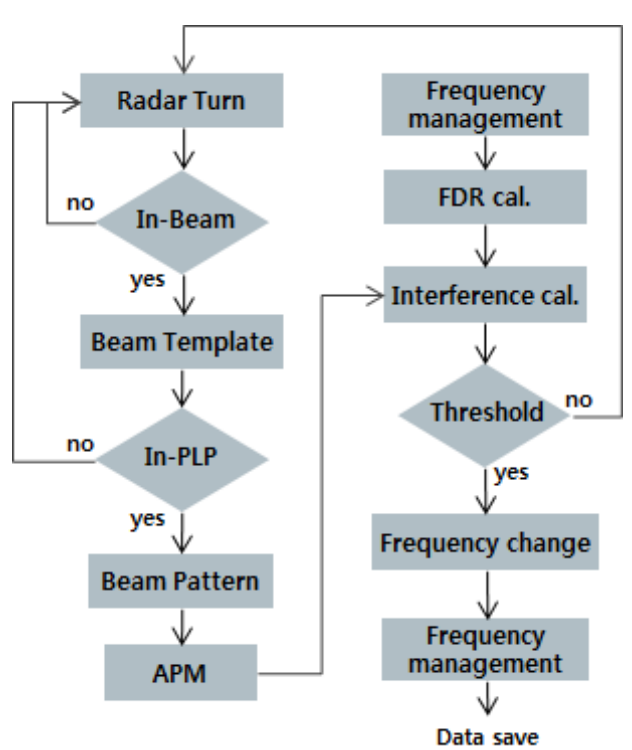

그림 5. M\&S 모델 흐름도

Fig. 5. The flow diagram of M\&S model.

위치와 구동 시작 각도, 빔 정보가 입력되면 레이다가 회 전을 시작한다. 이후 상대 레이다가 송신 빔 폭 안에 들어 왔을 때 빔 템플릿 정보를 이용하여 빔의 펄스가 방사된 시간들을 계산하고, 검출 모델이 계산된 펄스 방사 시간 들이 PLP 구간에 들어갔는지 판단한다. 만일 PLP 구간에 펄스가 들어가면 해당 빔의 패턴과 $\mathrm{APM}$ 을 이용하여 대 기 전파 손실을 계산하고, 동시에 사용 중인 주파수를 이 용하여 FDR을 계산한다. 계산된 값들을 이용하여 피간섭 레이다에 수신된 간섭 크기를 계산한다. 최종 계산된 간 섭 크기를 임계값과 비교하여 이상일 시 간섭으로 간주 하고, 해당 주파수를 삭제하고, 임의의 주파수로 이격한 다. 전파 간섭이 검출되지 않을 때는 사용 주파수는 레이 다가 회전할 때마다 계속 임의적으로 변하며, 간섭으로 삭제된 주파수는 10 회 회전 후 복원된다.

\section{III. 간섭 시뮬레이션}

\section{3-1 시나리오}

레이다를 운용할 때 위치 선정이 매우 중요하다. 적의 대공 침투를 감시하고, 아군의 항공기를 관리하기 위해서 는 작전 구역 내에 전파가 모두 도달해야 한다. 산악 지역 


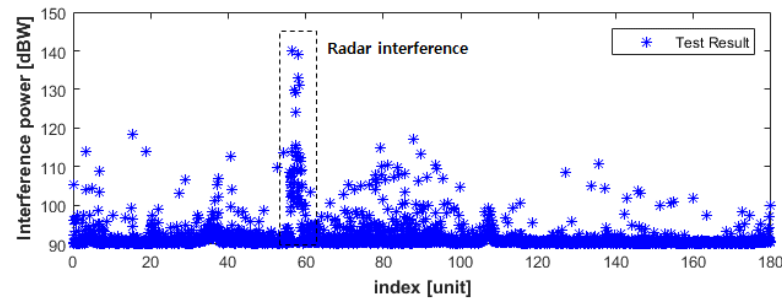

그림 6. 레이다 간섭 신호 실측 데이터

Fig. 6. The measured data of radar interference signal.

에서 레이다를 운용할 때 지형에 의해 전파가 도달하지 못하는 구역은 많이 존재한다. 이러한 차폐구역을 없애기 위해서는 많은 레이다를 가깝게 설치할 수밖에 없고, 이 로 인해 레이다 간 간섭이 발생하게 된다. 실제 레이다에 측정된 간섭신호를 보면 그림 6과 같다. 일정 방위에서 주기적인 간섭 신호가 연속적으로 들어오는 것을 볼 수 있다. 이는 해당 방위에 위치한 다른 레이다로부터 수신 된 간섭 신호이다.

본 논문에서는 간섭 현상을 모의하기 위해 그림 7과 같 이 분석 개념을 설정하였다. 간섭 레이다와 피간섭 레이 다로 상호간 전파 간섭 영향성을 분석하고, 각 레이다는 정해진 서로 다른 빔 템플릿에 따라 빔을 운용한다. 두 레 이다의 위치는 한반도 임의의 산악 지역 중 가시선(line of sight) 확보가 가능한 곳으로 설정하였으며, 수행된 시 뮬레이션 값은 표 1 과 같다.

실시간 회전하고 있는 레이다 환경에서 구동 시작 각도 는 전파 간섭 영향성 분석에 있어 중요한 변수 중 하나이 다. 그림 8 과 같이 구동 시작 각도에 따라 상대 레이다에

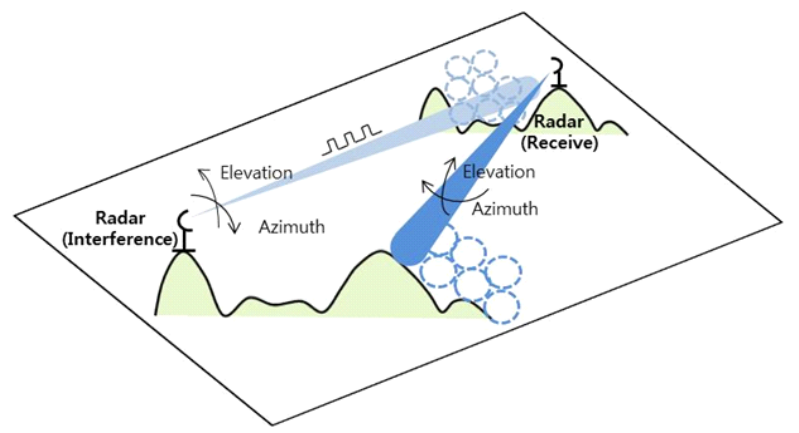

그림 7. $\mathrm{M} \& \mathrm{~S}$ 모델 분석 시나리오 개념도

Fig. 7. The concept of M\&S model analysis scenario.
표 1. M\&S 모델 시나리오 요약

Table 1. Summary of M\&S model scenario.

\begin{tabular}{|c|c|c|}
\hline Item & Interference radar & Receive radar \\
\hline Frequency & S-band & S-band \\
\hline Power & $30 \mathrm{~kW}$ & $20 \mathrm{~kW}$ \\
\hline Antenna gain & $33.2 \mathrm{~dB}$ & $34.8 \mathrm{~dB}$ \\
\hline Bandwidth & $3 \mathrm{MHz}$ & $3 \mathrm{MHz}$ \\
\hline Distance of radar & \multicolumn{2}{|c|}{$45 \mathrm{~km}$} \\
\hline Starting angle of rotation & \multicolumn{2}{|c|}{$180^{\circ}, 145^{\circ}$} \\
\hline Sensitivity & \multicolumn{2}{|c|}{$>20 \mathrm{~dB}$} \\
\hline Atmosphere & \multicolumn{2}{|c|}{ Standard } \\
\hline Frequency operation & Basic frequency, Sectored frequency \\
\hline
\end{tabular}

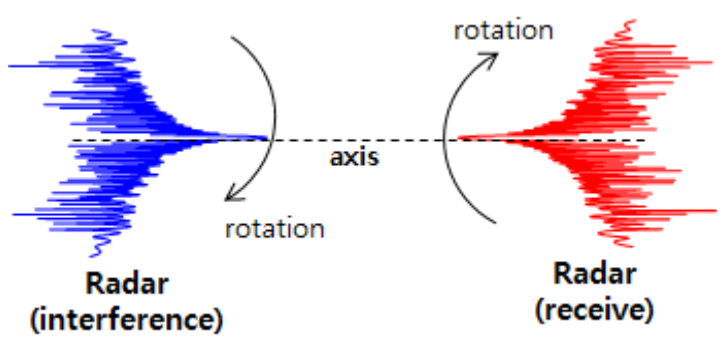

(a) $180^{\circ}$ 차이

(a) Difference $180^{\circ}$

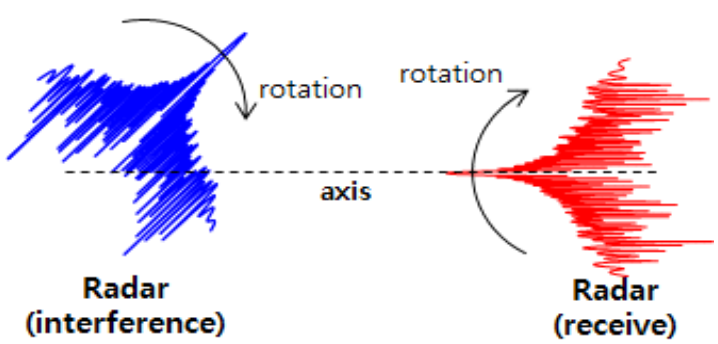

(b) $145^{\circ}$ 차이

(b) Difference $145^{\circ}$

그림 8. 구동 시작 각도에 따른 빔 방사

Fig. 8. Propagation beam pattern according to starting angle of rotation.

빔이 향할 때 다른 레이다의 빔 방향이 정해진다. 구동 시 작 각도 차이가 $180^{\circ}$ 일 경우는 두 레이다가 만나는 빔은 방위각 기준으로 주엽(main lobe)이 만나게 되면서 전파 간섭이 증가되는 특수한 경우이다. 그 외에 다른 각도일 경우는 주엽과 부엽(side lobe)이 만나 간섭 크기는 줄지 

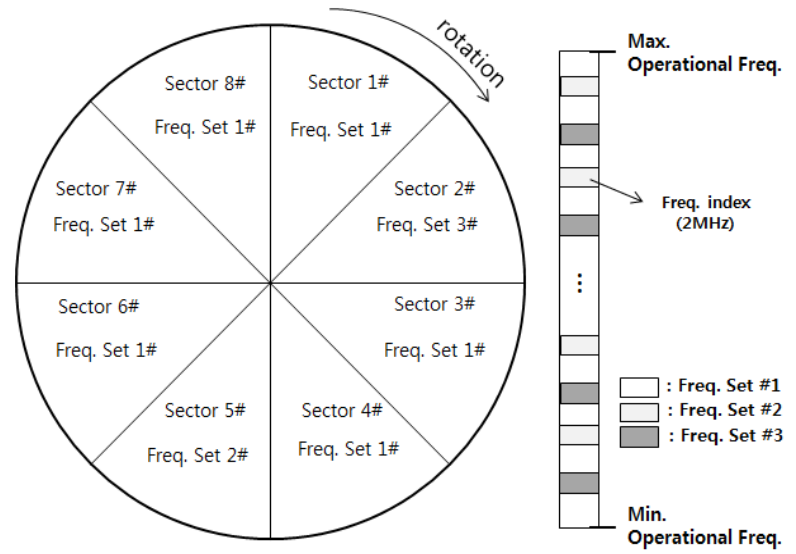

그림 9. 섹터 주파수 운용 개념

Fig. 9. The concept of sectored-frequency operation.

만, 간섭 기회 시간이 증가하게 되는 일반 경우에 해당된다.

주파수 운용은 전 방위 동일 주파수를 사용하는 기본 주파수와 섹터별 주파수를 다르게 관리하는 섹터 주파수 로 구분하였다이,[10]. 섹터 주파수는 그림 9와 같이 전파 간섭을 줄이기 위해 전 방위를 일정 각도로 나눠 섹터를 지정하고, 각 섹터마다 개별적으로 주파수를 운용하는 방 식이다. 이 방식은 상대 레이다가 위치한 섹터의 주파수 를 이격된 주파수로 구성하여 전파 간섭을 줄이는 효과 를 볼 수 있다. 본 논문에서는 두 가지 주파수 운용에 따 른 전파 간섭 영향성을 분석하였다.

\section{3-2 시뮬레이션 결과}

그림 10 은 시작 구동 각도가 $180^{\circ}$ 차이가 나는 레이다에 대해 250회 회전 시뮬레이션 1회 수행 시 수신된 간섭 크 기 결과이다. 기본 주파수를 사용할 시 최대 약 -105.76 $\mathrm{dBW}$, 평균 $-128.96 \mathrm{dBW}$ 의 크기를 가지며, 섹터 주파수 사용 시 최대 약 $-139.79 \mathrm{dBW}$, 평균 $-154.01 \mathrm{dBW}$ 의 크 기를 가진다. 기존 주파수 대비 섹터 주파수 운용 시 수신 되는 간섭의 크기가 평균 $25 \mathrm{~dB}$ 이상 감소하며, 최대 수 신되는 크기의 경우 $34 \mathrm{~dB}$ 이상 감소한다. 또한 성능 지 표 중 하나인 간섭 받은 레이다 회전 비율 결과의 경우 250 회 회전 중 각각 81,59 회로 섹터 주파수 운용 시 약 $9 \%$ 향상되었다.

전파 간섭을 받아 주파수가 삭제되면 사용 가능한 주

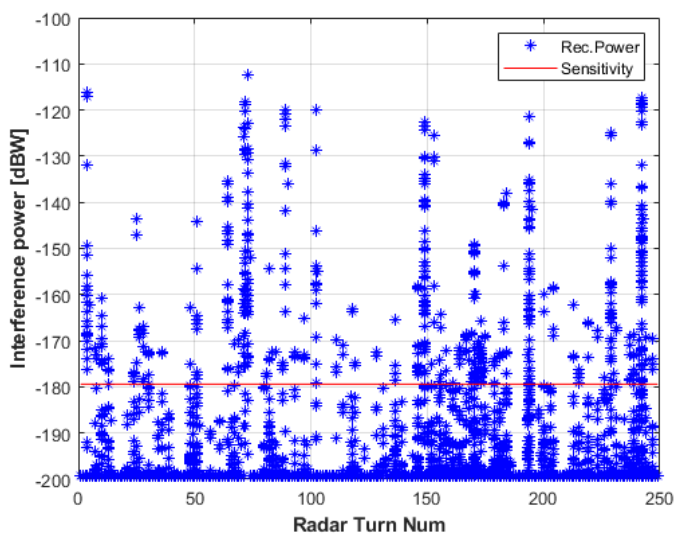

(a) 기본 주파수 운용

(a) Standard frequency operation

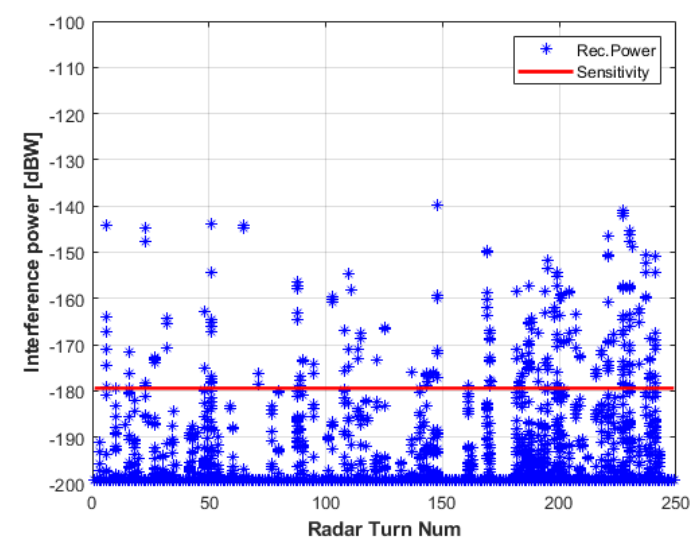

(b) 섹터 주파수 운용

(b) Sectored frequency operation

그림 10. 수신 간섭 크기 결과

Fig. 10. Result of received jamming power.

파수가 점차적으로 감소하고, 다른 주파수에서 간섭이 올 시 대응성이 떨어져 탐지 성능이 감소한다. 섹터 주파수 는 간섭 레이다가 속한 섹터에는 소수의 이격된 주파수 를 운용하기 때문에 간섭이 발생할 경우 해당 섹터의 가 용성은 떨어지지만, 전 방위 주파수 가용성 측면에서는 이점이 있다. 여기에서 주파수 가용성이란 전체 주파수 대비 사용 가능한 주파수 수의 비로 정의된다. 두 주파수 운용에 따른 주파수 가용성 결과는 그림 11 과 같이 섹터 주파수 이용 시 최대 약 $10 \%$ 이상 높은 가용성을 가진 것을 볼 수 있다.

전파 간섭이 검출되면 주파수 이격 시 임의로 변하기 


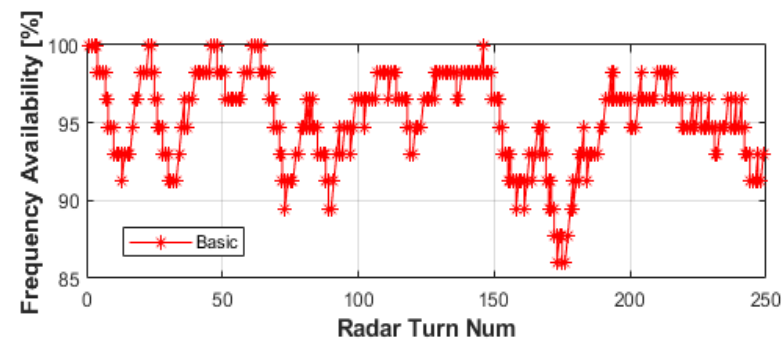

(a) 기본 주파수 운용

(a) Standard frequency operation

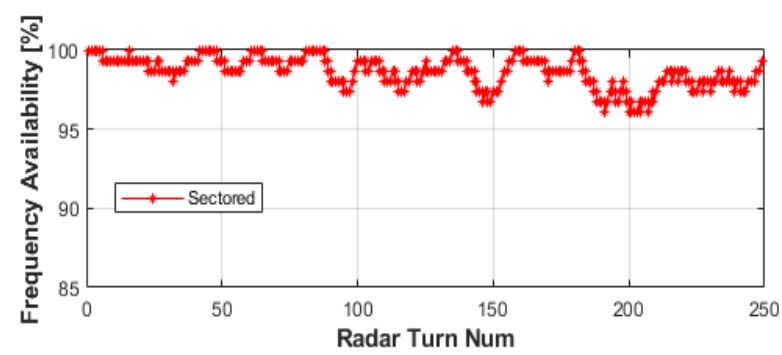

(b) 섹터 주파수 운용

(b) Sectored frequency operation

그림 11. 주파수 가용성 결과

Fig. 11. Result of frequency availability.

때문에 250회전의 시뮬레이션 1회로 특성을 단정하기에 는 무리가 있다. 따라서 본 논문에서는 추가적으로 전파 간섭 영향을 보다 정확하게 정량화하기 위해 250회전의 시뮬레이션을 150 회 누적하여 진행하였다. 그 결과, 그림 12 와 같이 수신된 간섭의 평균 크기와 표준 편차는 기본 주파수 이용 시 $-126.10 \mathrm{dBW}, 3.49 \mathrm{dBW}$, 섹터 주파수 이 용 시 $-155.79 \mathrm{dBW}, 1.32 \mathrm{dBW}$ 의 크기를 가진다.

간섭받은 레이다 회전 비율의 분포는 그림 13 과 같으 며, 기본 주파수 운용 시 총 회전 중 평균 약 $32.75 \%$ 의 회전에서 전파 간섭이 검출되었으며, 섹터 주파수 운용 시 $28.94 \%$ 가 검출되었다.

그림 12 및 13의 결과는 앞서 3-1절에서 언급했듯이 간 섭 크기가 최대가 될 수 있는 특수한 경우이다. 이를 제외 한 일반 경우가 실제 레이다 운용 시 발생할 수 있는 일 반적인 환경이다. 대표적으로 $145^{\circ}$ 의 시작 구동 각도 차 이를 두었을 경우의 결과는 그림 14 및 15 와 같다. 특수 경우, 대비 주엽에 의해 간섭이 검출될 시간은 증가하지 만, 하나의 레이다가 주엽을 향할 때 다른 레이다는 부엽

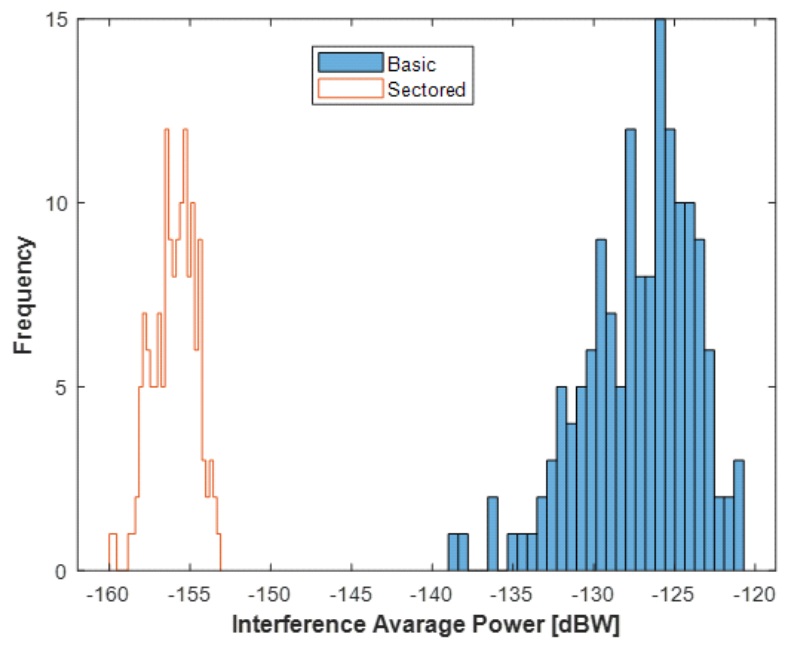

그림 12. 수신 간섭 평균 크기 분포(특수 경우 $180^{\circ}$ )

Fig. 12. Distribution of received interference average power (Special case $180^{\circ}$ ).

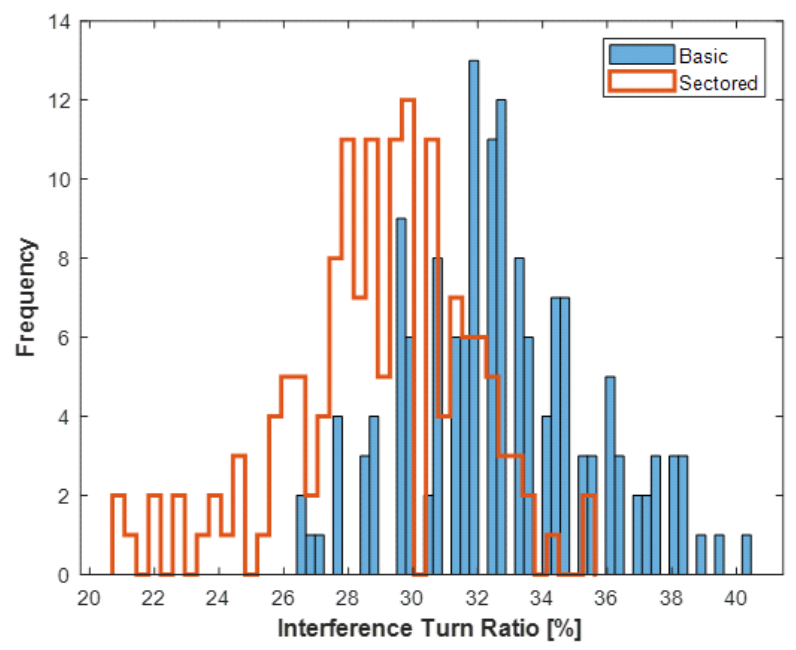

그림 13. 간섭받은 회전 비율 분포(특수 경우 $180^{\circ}$ )

Fig. 13. Distribution of turn ratio affected by interference (Special case $180^{\circ}$ ).

으로 안테나 이득이 감소하여 상대적으로 낮은 크기의 간섭 신호가 들어온다. 동시에 낮은 간섭 크기로 수신되 기 때문에 간섭받은 회전 수 또한 낮은 분포를 보인다. 기 본 및 섹터 주파수 운용을 비교했을 시 그림 14 와 같이 평균 크기는 $-143.83 \mathrm{dBW},-169.96 \mathrm{dBW}$ 로 섹터 주파수 운용 시 더 낮은 평균 간섭 크기를 가지며, 표준 편차는 


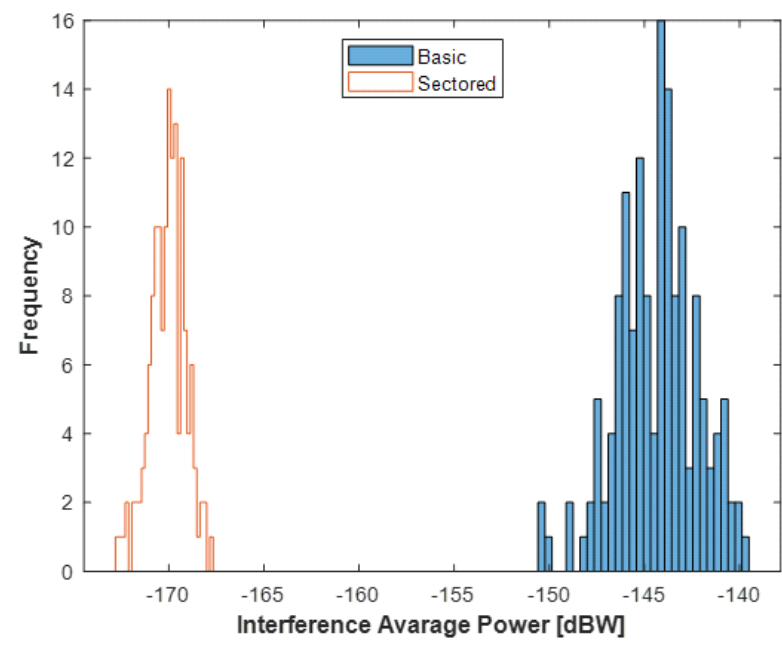

그림 14. 수신 간섭 평균 크기 분포(일반 경우 $145^{\circ}$ )

Fig. 14. Distribution of received interference average power (normal case $145^{\circ}$ ).

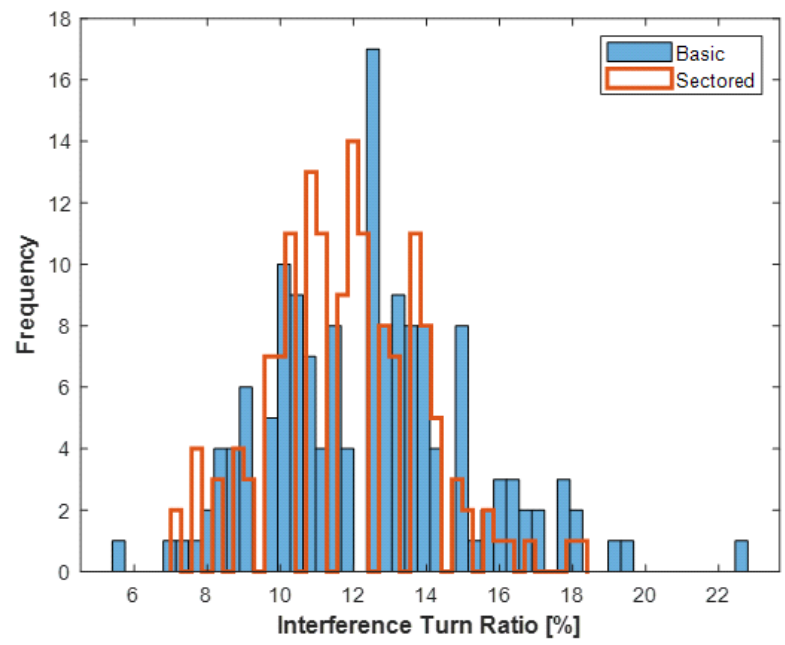

그림 15. 간섭받은 회전 비율 분포(일반 경우 $\left.145^{\circ}\right)$

Fig. 15. Distribution of turn ratio affected by interference (Normal case $145^{\circ}$ ).

각각 $2.15 \mathrm{dBW}, 0.93 \mathrm{dBW}$ 로 섹터 주파수가 안정화된 결 과를 가진다. 간섭 받은 회전 비율의 분포는 그림 15 와 같 으며 전체 회전 중 평균 $12.41 \%$ 와 $11.85 \%$ 의 회전에서전 파 간섭이 검출되었다.

결과를 종합해 보면 구동과 관계없이 수신되는 간섭 크기와 주파수 가용성 그리고 간섭받은 회전 비율 측면
표 2. $\mathrm{M} \& S$ 모델 결과 요약

Table 2. Summary of M\&S model result.

\begin{tabular}{|c|c|c|c|c|}
\hline $\begin{array}{l}\text { Starting } \\
\text { angle of }\end{array}$ & \multicolumn{2}{|c|}{ Item } & Basic & Sectored \\
\hline \multirow{3}{*}{$\begin{array}{c}180^{\circ} \\
\text { (Special } \\
\text { case) }\end{array}$} & \multirow{2}{*}{$\begin{array}{c}\text { Interference } \\
\text { power } \\
{[\mathrm{dBW}]}\end{array}$} & Average & -126.10 & -155.79 \\
\hline & & $\begin{array}{l}\text { Standard } \\
\text { deviation }\end{array}$ & 3.49 & 1.32 \\
\hline & \multicolumn{2}{|c|}{$\begin{array}{l}\text { Turn ratio affected by } \\
\text { interference }[\%]\end{array}$} & 32.75 & 28.94 \\
\hline \multirow{3}{*}{$\begin{array}{c}145^{\circ} \\
\text { (Normal } \\
\text { case) }\end{array}$} & \multirow{2}{*}{$\begin{array}{c}\text { Interference } \\
\text { power } \\
{[\mathrm{dBW}]}\end{array}$} & Average & -143.83 & -169.96 \\
\hline & & $\begin{array}{l}\text { Standard } \\
\text { deviation }\end{array}$ & 2.15 & 0.93 \\
\hline & \multicolumn{2}{|c|}{$\begin{array}{l}\text { Turn ratio affected by } \\
\text { interference }[\%]\end{array}$} & 12.41 & 11.85 \\
\hline
\end{tabular}

에서 기본 주파수보다 섹터로 구분한 주파수 운용이 간 섭 영향을 덜 받는 것으로 분석된다.

\section{IV. 결 론}

레이다 간 전파 간섭은 탐지성능을 저하시킨다. 레이다 의 수가 증가하고 주파수가 부족한 상황에서 전파 간섭의 영향성은 증가한다. 전파 간섭은 빔 운용 및 주파수 운용에 따라 그 형태가 다양하고 임의적으로 발생하여 예측하기 어렵다. 이를 위해 본 논문에서는 실제 레이다의 주파수 및 빔 운용을 모사할 수 있는 M\&S 도구를 개발하여 주파 수 운용에 따른 상호간 전파 간섭을 예측 및 분석하였다. 그 결과, 표 2 와 같이 기본 주파수 운용보다 섹터 주파수 운용 시 전파 간섭이 줄어드는 것을 확인할 수 있었다.

개발된 M\&S 도구를 통해 기존 설치된 레이다 간 발생 되는 전파 간섭을 모의하여 주파수 운용에 따른 예상 성 능을 도출할 수 있으며, 새롭게 설치될 레이다에서 발생 가능한 전파 간섭을 예측 및 대응할 수 있다. 추후 전파 간섭에 의해 기동하는 표적의 탐지 성능 변화를 복합적 으로 예측 및 분석할 수 있을 것으로 기대된다.

\section{References}

[1] Characteristics of and protection criteria for terrestrial 
radars operating in the radiodetermination service in the frequency band 8,500 10,680 MHz band, ITU-R Recommendation M.1796, May 2012.

[2] J. Y. Yang, J. S. Jung, and Y. K. Kwag, "Inter-radar interference impact analysis on the basis of radar interference protection criteria," The Journal of Korean Institute of Electromagnetic Engineering and Science, vol. 19, no. 6, pp. 657-662, Jun. 2008.

[3] S. A. Mostafa, "Estimation of the hit probability and its effect on the performance of frequency hopping radar system," in The 2nd International Conference on Wireless Broadband and Ultra Wideband Communications (AusWireless 2007), Australia, NSW, 2007, pp. 75-75.

[4] T. Foreman, "A radar-to-radar interference prediction model," in IEEE 1991 International Symposium on Electromagnetic Compatibility, Cherry Hill, NJ, 1991, pp. 200-205.

[5] J. Kim, J. S. Jung, Y. K. Kwag, J. G. Kim, and Y. C. Jeon, "Analysis of interference protection criteria for interoperability of radar systems," The Journal of Korean Institute of Electromagnetic Engineering and Science, vol. 25, no. 4, pp. 434-441, Apr. 2014.

박 명 훈 [LIG넥스원/선임연구원]

https://orcid.org/0000-0002-5217-0365

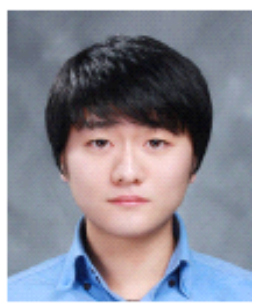

2014년 2월: 한국항공대학교 항공전자공 학과 (공학사)

2016년 2월: 한국항공대학교 항공전자정 보공학과 (공학석사)

2016년 1월 현재: LIG넥스원 SW연구소 선임연구원

[주 관심분야] 레이다, $\mathrm{M \& S}$, 안테나 등
[6] Frequency and distance separations, Recommendations ITU-R SM.337-4, 2007.

[7] B. R. Mahafza, Atef Z. Elsherbeni, MATLAB Simulation for Radar Systems Design, Boca Raton, FL, Chapman \& Hall, 2004.

[8] H. W. Moon, M. H. Jeon, W. J. Kim, S. K. Oh, J. H. Lee, and S. Kwon, et al., "Development of exponential model of Korea for improved altitude estimation performance of high-altitude target at radar system," The Journal of Korean Institute of Electromagnetic Engineering and Science, vol. 23, no. 7, pp. 831-839, Jul. 2012.

[9] S. W. Seo, S. M. Lee, and Y. S. Kim, "Antenna polarization isolation and resource control for frequency interference reduction between opposite sectors," The Journal of Korean Institute of Communication and Information Sciences, vol. 40, no. 6, pp. 1014-1023, Jun. 2015.

[10] S. W. Kwon, Y. W. Kwon, and H. S. Kim, "Method and apparatus for selecting minimum interference frequency based on jamming detection with minimum time resource and statistical processing," The Korean Intellectual Property Office, Application number 10-2018-0088718, 2018.

\section{권 세 웅 [LIG넥스원/수석연구원]}

https://orcid.org/0000-0002-8959-4452

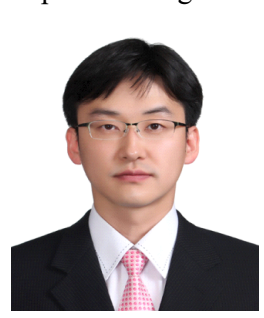

1999년 2월: 연세대학교 전파공학과 (공학

사)

2002년 2월: 연세대학교 전기컴퓨터공학

과 (공학석사)

2009년 8월: 연세대학교 전기전자공학과

(공학박사)

2009년 7월 현재: LIG넥스원 레이다연구

소 수석연구원

[주 관심분야] 능동위상배열레이다, 전파전파 등 
THE JOURNAL OF KOREAN INSTITUTE OF ELECTROMAGNETIC ENGINEERING AND SCIENCE. vol. 30, no. 10, Oct. 2019.

전 우 중 [LIG넥스원/선임연구원]

https://orcid.org/0000-0003-3974-0631

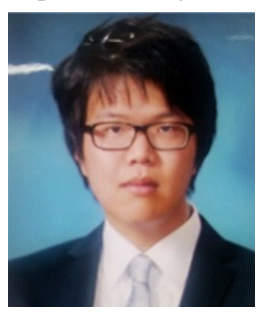

2010년 7월: 서울대학교 전기공학과 (공학 사)

2016년 2월: 서울대학교 전기공학과 (공학 석사)

2016년 1월 현재: LIG넥스원 SW연구소 선임연구원

[주 관심분야] $\mathrm{M \& S}$, 레이다, 제어 등
유 승 기 [LIG넥스원/수석연구원]

https://orcid.org/0000-0003-3473-7994

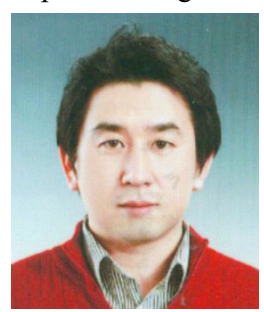

2002년 2월: 한양대학교 지구해양과학 (이 학사)

2004년 8월: 한양대학교 해양환경과학 (이 학석사)

2013년 8월: 한양대학교 해양융합과학 (이 학박사)

2010년 1월 현재: LIG넥스원 SW연구소 수석연구원

[주 관심분야] 수중음향, $\mathrm{M} \& S$, 레이다 등

이 기 원 [LIG 넥스원/수석연구원]

https://orcid.org/0000-0003-2545-7579

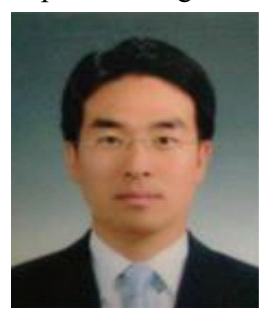

2000년 2월: 충남대학교 전기공학과 (공학 사)

2002년 8월: 충남대학교 전기공학과 (공학 석사)

2002년 7월 현재: LIG 넥스원 레이다 연 구소 수석연구원

[주 관심분야] 레이다 체계설계, 안테나

리즘 등

[주 관심분야] 항공제어, $\mathrm{M \& S}$, 추적 알고

2016년 2월: 인하대학교 항공우주공학과 (공학석사)

2016년 1월 현재: LIG넥스원 SW연구소 선임연구원 